\title{
Chronic pain management in the obese patient: a focused review of key challenges and potential exercise solutions
}

This article was published in the following Dove Press journal:

Journal of Pain Research

9 February 2015

Number of times this article has been viewed

\section{Laura Ann Zdziarski \\ Joseph G Wasser \\ Heather K Vincent}

Department of Orthopaedics and Rehabilitation, Division of Research, Interdisciplinary Center for Musculoskeletal Training and Research, University of Florida, Gainesville, FL, USA
Correspondence: Heather K Vincent Department of Orthopaedics and Rehabilitation, Division of Research, UF Orthopaedics and Sports Medicine Institute (OSMI), PO Box I I 2727, Gainesville, FL 326II, USA

Tel +I 3522737459

Fax +I 3522737388

Email vincehk@ortho.ufl.edu

\begin{abstract}
In obese persons, general and specific musculoskeletal pain is common. Emerging evidence suggests that obesity modulates pain via several mechanisms such as mechanical loading, inflammation, and psychological status. Pain in obesity contributes to deterioration of physical ability, health-related quality of life, and functional dependence. We present the accumulating evidence showing the interrelationships of mechanical stress, inflammation, and psychological characteristics on pain. While acute exercise may transiently exacerbate pain symptoms, regular participation in exercise can lower pain severity or prevalence. Aerobic exercise, resistance exercise, or multimodal exercise programs (combination of the two types) can reduce joint pain in young and older obese adults in the range of $14 \%-71.4 \%$ depending on the study design and intervention used. While published attrition rates with regular exercise are high $(\sim 50 \%)$, adherence to exercise may be enhanced with modification to exercise including the accumulation of several exercise bouts rather than one long session, reducing joint range of motion, and replacing impact with nonimpact activity. This field would benefit from rigorous comparative efficacy studies of exercise intensity, frequency, and mode on specific and general musculoskeletal pain in young and older obese persons.
\end{abstract}

Keywords: exercise, inflammation, kinesiophobia, obese, pain

\section{Introduction}

Obesity negatively impacts the musculoskeletal system. ${ }^{1}$ Excessive weight increases mechanical stress to the joints and tissues of the body, ${ }^{2}$ and induces physical limitations and bodily pain. Self-reported bodily pain symptoms increase with progressively higher body mass index (BMI) values. ${ }^{3}$ The confluence of pain and weight-related physical discomfort exacerbates the decline in physical function. This is a serious issue because chronic pain mediates obesity-induced impairment and the eventual decline of fitness and health-related quality of life. ${ }^{4-6}$

Obesity rates in the US are $35 \%$ for adults and $17 \%$ for youth, and only $21 \%$ of Americans meet the recommended levels of physical activity for health. ${ }^{7}$ This is a serious issue because the loss of muscle strength due to inactivity contributes to worsening joint pain in adults. ${ }^{8}$ Moreover, adults, especially women, with high fat mass-to-muscle ratios have widespread musculoskeletal pain ${ }^{9}$ and have higher rates of physical inactivity. ${ }^{10}$ Often, obese adults suffer from negative psychological outlook, which perpetuates sedentary behavior. For obese children, pain reduces mobility, participation in exercise, and overall happiness. ${ }^{6}$ Children with BMI values exceeding the 95 th percentile reported double the prevalence of pain than nonobese counterparts (44.8\% vs 19.1\%), and the pain is related to skeletal deformity and musculoskeletal dysfunction. ${ }^{11}$ Emerging 
evidence suggests that obesity mediates pain and the psychological state through a mechanism of inflammation. ${ }^{12}$ This focused review describes this proposed relationship between obesity, musculoskeletal pain, inflammation, and psychological status. Exercise solutions that reduce chronic pain are presented.

\section{Effects of pain on physical activity in obesity}

Obesity is associated with comorbidities and discomforts that can negatively affect psychological well-being and perceptions about staying physically active. ${ }^{13,14}$ These include heart disease and heart failure, fibromyalgia, asthma, gout, diabetes, anxiety, and depression. Increased muscle effort can trigger physical discomforts such as dyspnea, chest pain, muscle fatigue, and psychological discomforts such as stigma, fear of falling, and low self-efficacy. ${ }^{14-16}$ This is problematic for practitioners and those affected because physical activity and exercise are main tenets of weight management programs and long-term health. ${ }^{13}$

Both obese children and adults experience pain symptoms most frequently in the axial and load-bearing segments of the body such as the neck, low back, ${ }^{10,17,18}$ and lower limb..$^{6,19,20}$ Chronic joint pain can also occur in the non-weight-bearing joints of the upper body such as the shoulder and hand, ${ }^{10,19}$ and in the facets of the lumbar spine. ${ }^{21}$ Obese persons suffer from multisite pain, ${ }^{22}$ and morbidly obese are over twice as likely to report consistent, severe pain symptoms than normal weight individuals. ${ }^{23}$ Longitudinal evidence shows that high BMI precedes and independently predicts foot joint pain ${ }^{20}$ and knee pain. ${ }^{24}$

Chronic musculoskeletal pain hinders participation in regular exercise programs $s^{25,26}$ and performance of normal functional tasks. ${ }^{27,28}$ Among obese disabled women, 63.6\% reported that the major personal barrier to increasing physical activity levels is pain. ${ }^{29}$ Population-based cohorts show that irrespective of age, race, and sex, obese people with joint pain are $44 \%$ more likely to be physically inactive. ${ }^{30}$ Pain may exacerbate the obesity-related barriers to participation in exercise (stigma, embarrassment, lack of motivation, physical discomfort). ${ }^{31}$ For example, excessive weight compresses axial structures and load-bearing joints and misaligns the bone-to-bone interfaces in joints, especially in the knee and spine. ${ }^{2,32}$ Gross motor tasks that involve moving significant knee flexion and extension to move the body vertically (eg, stair ascent and descent, timed-up-and-go activities, chair rise, getting in and out of a car, rising from a supine position on the floor, picking up objects from the floor) are especially difficult for the obese individual. ${ }^{27,33,34}$ Even more refined movements such as a one-legged stance or cutting toenails are more challenging with rising BMI values. ${ }^{27}$ Some of these activities require static positions such as standing, whereas others involve transient loading such as stairs or walking. When pain is present, the discomfort of both single- and dual-limb tasks in obesity can reinforce negative views about being active. Hence, a challenge for practitioners is how to motivate obese patients to overcome the barriers and work through exercise discomforts sufficiently to elicit physical functional improvements.

With activities of daily living, there are compensatory responses to musculoskeletal pain that include less movement excursion (eg, short steps and less joint motion), ${ }^{35}$ slower velocity of movement and initiation of gait, ${ }^{36,37}$ co-contraction of muscles, and asymmetric loading. ${ }^{35,36,38}$ Slower execution of movement is a method of minimizing peak forces and impulse of force loading. In people with unilateral or bilateral joint pain of the knee, ${ }^{39}$ motion is achieved with asymmetric joint flexion angles at the knee, hip adduction moments and internal rotation, and toe out angles. Pain causes individuals to change movement patterns during daily tasks to offload the painful limb and overload the non-affected limb. People with chronic hip pain who perform actions like sit-to-stand reduce the impact force by $18 \%$ on the painful limb and increase the moments of the knee of the non-affected limb by $19 \% .{ }^{40}$ In addition to joint loading, a functional compensation to pain is alteration of the flexion-extension activation of muscles surrounding a painful joint. Specifically, maximum flexion moments are reduced during mid-stance phase of walking, perhaps to offset the load-induced pain. ${ }^{38}$ Deterioration of normal gait and mobility disability may be affected by the combined stressors of lower body joint pain. ${ }^{41}$

\section{Interrelated obesity factors that contribute to chronic musculoskeletal pain}

Among several potential mechanisms that may mediate the relationships between pain in obesity ${ }^{42}$ are mechanical loading, ${ }^{43}$ inflammation, ${ }^{44}$ and psychological status. ${ }^{23,45}$ Obesity itself is associated with high mechanical stresses on the body ${ }^{26}$ and high tissue inflammation. ${ }^{46}$ Moreover, obesity is associated with several negative psychological alterations that include pain catastrophizing and fear of movement due to pain. It has recently been suggested that there is an interrelationship between mechanical loading, chronic pain, inflammation, and psychological status. ${ }^{1,38,47}$ It remains unclear, however, whether the inflammation and psychological stress 
directly contribute to obesity, or whether obesity results in inflammation and stress that propagate weight gain. Figure 1 shows the proposed relationships between these factors. Obesity increases musculoskeletal stress and inflammation and reduces psychological health. Each factor, however, may also independently and directly impact the other factors in this relationship. For example, depression or chronic mental stress may lead to systemic inflammation and disinterest in healthy lifestyle habits. Alternatively, obesity can produce low self-efficacy and self-worth, both of which lead to psychological stress and inflammation. In each situation, the intersection of these collective factors is strongly related to pain in the musculoskeletal system.

\section{Mechanical loading}

Body weight is directly related to the loading on the musculoskeletal system. Overweight and obesity increase the risk by two to four times for clinically important joint pain increase over 2 years compared to normal weight. ${ }^{48}$ With progressively higher classification of obesity, compressive loading increases across joints. In knee osteoarthritis (OA), people with class $2+$ obesity have greater peak compressive knee forces than overweight people $(2,293 \mathrm{~N}$ vs $2,182 \mathrm{~N}) .{ }^{49}$ This compression is accompanied by greater, although not significant, knee shear forces and patellofemoral forces acting at the knee. ${ }^{49}$ Obese persons have been shown to have inadequate strength to control loading and maintain normal alignment of joints. Subsequently, aberrant biomechanics during locomotor tasks occur. In the feet, muscle weakness precludes adequate arch support, and the foot joints ${ }^{50}$ experience excessive and unaccustomed compressive plantar loading. ${ }^{11,51}$ In peripheral joints

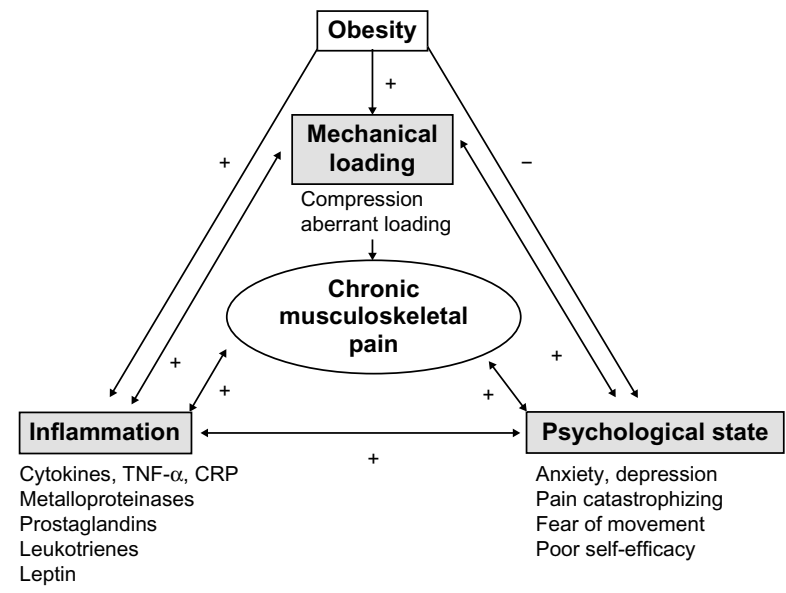

Figure I Proposed relationships between mechanical loading, inflammation and psychological state in obesity-related musculoskeletal pain

Notes: + denotes an amplification of the factor; - denotes a suppression of the factor. Abbreviations: TNF- $\alpha$, tumor necrosis factor- $\alpha$; CRP, C-reactive protein. like the knee, there is a relative strength deficit of the knee flexors and extensors which contributes to misalignment of the tibiofemoral joint (favoring genu valgum). ${ }^{49}$ The combination of the loading and poor mechanics directly increases the tissue stresses to the articular cartilage and connective tissues within the joints. Obesity can induce joint pain by these pathomechanical mechanisms: ${ }^{52}$ 1) altered distribution of weight loading occurs on cartilaginous areas of joint unaccustomed to loading and 2) loading may intensify across a small cross-sectional area of the joint and focally cause tissue damage. Because there is a compensatory offloading from painful areas to areas that are not in pain, there is an eventual progression of mechanical stress and pain to the loaded area.

In axial joints, the distribution of adipose tissue can shift the center of mass and affect mechanical alignment of axial joints. For example, abdominal adiposity shifts the center of mass forward ${ }^{53}$ and increases the posterior mechanical loading to structural areas of the spine that articulate, such as the facet joints of the vertebrae. Back pain is the net result. Even with upper body tasks, scapular kinematics are different in obese people compared to people with healthy weight. Scapulorthoracic motion comprises greater scapular upward rotation in obesity during arm lift and when lifting an object. ${ }^{54}$ While this movement strategy is a compensation to manage arm mass, this aberrant pattern is related to shoulder rotator cuff tears and pain. ${ }^{54}$

Soft tissues are also victims of obesity-loading stress. Intervertebral disks are susceptible to degeneration in obese people, but the mechanism for disk breakdown remains speculative. ${ }^{9}$ Obesity compresses the vertebral column and narrows disk spaces, and progression of the degeneration includes neuroforaminal stenosis and altered biomechanics, ${ }^{55}$ both of which may contribute to pain. Achilles, patella, and elbow tendinopathies are related to the presence of the metabolic syndrome. ${ }^{47}$ Magnetic resonance imaging showed that the prevalence of tendon and ligamentous pathologies of the ankle is 1.59 times higher in persons with BMI $>25 \mathrm{~kg} / \mathrm{m}^{2}$ compared to people with lower BMI values. ${ }^{56}$

\section{Inflammation}

Inflammation is a state that fosters nociception in damaged musculoskeletal tissues and prevents healing. ${ }^{47}$ Inflammation can be an activator of pain in obesity, and conversely can be activated by obesity-related mechanical stressors in tissue. Cytokines can activate central nervous system tissues and mediate a "sickness response", fatigue, depressive symptoms, and hyperalgesia. ${ }^{57}$ Chronic pain stresses and exhausts the 
hypothalamic-pituitary axis (HPA), leading to perpetual reactivation of a sensitized stress response. ${ }^{12}$ Hypocortisolism normally occurs after a stressful event, but over the long term, cortisol responses are delayed. Cortisol dysfunction results in systemic inflammation, and inflammation itself initiates and prolongs pain. ${ }^{58}$ This endocrine response can be intensified in people who exaggerate their responses to pain. For example, hypervigilance to pain, catastrophizing, negative thinking, or maladaptive thoughts or avoidant-coping strategies are behaviors that are related to frequent or prolonged stimulation of the HPA. ${ }^{12}$

Pro-inflammatory proteins such as cytokines are released by immune cells, adipocytes, and other tissues. ${ }^{57} \mathrm{C}$-reactive protein (CRP) and interleukins (ILs) are elevated in persons with chronic musculoskeletal pain (low back pain [LBP], knee pain, foot pain, joint pain) $)^{19,42,59}$ and more so in obese persons compared to persons with normal weight. Obese people have high adipose tissue volume in the viscera and the intramuscular and perimuscular spaces. Excess fat volume effects are insidious in nature as they produce high levels of CRP, tumor necrosis factor- $\alpha$ (TNF- $\alpha$ ), IL-6, IL-1 $\beta$, and leptin, among others. ${ }^{46}$ High levels of these biomarkers are directly related to pain severity in persons with joint disease. ${ }^{60}$ Both systemic adipose tissue volume and local fat deposition may cause inflammation in areas that develop pain. As BMI and fat volume increase, the macrophages enter adipose tissue and are activated to behave like an infection is present. ${ }^{47}$ This state of "adisopathy" (sick fat tissue) promotes increased tissue pain. Some fat depots near joints act as local mediators of pain, such as the infrapatellar fat pad. This pad is highly innervated by $\mathrm{C}$-fiber neurons that secrete substance $\mathrm{P}$, which mediates pain and activates immune cells and local production of IL- 6 and TNF- $\alpha .{ }^{61}$ Thus, one explanation for non-weight-bearing joint pain in obese people may be a consequence of chronic inflammation. It is unclear how generalized exercise can reduce pain in non-weight-bearing joints.

The state of tissue loading impacts the level of inflammation. Both sedentary living and excessive loading activate systemic inflammation. ${ }^{47}$ When tissues are excessively loaded and aberrant gait patterns occur, degradation of the cartilaginous matrix begins, and inflammatory cytokines are released into the joint space and cause inflammation. ${ }^{62}$ Breakdown products from damaged extracellular matrix (fibronectin, hyaluranons) trigger release of TNF- $\alpha$, IL-1 $\beta$, IL- 6 , IL-8, and matrix metalloproteinases that perpetuate tissue damage.${ }^{61}$ One of the most studied models of this phenomenon is in knee OA.
With repeated loading trauma to the knee, inflammatory mediators are released from the synovium and cartilage of the joint. Cytokines, prostaglandins, proteolytic enzymes, and leukotrienes are released into the synovial fluid, and this promotes pain onset. ${ }^{61}$ This type of process also occurs in vertebral disks in persons with back pain. Systemic biomechanical loading with obesity can damage the disk and promote accumulation of breakdown products and tissue inflammation. ${ }^{55}$ Inflammatory processes propagate disk degeneration and structural instability. Nociception is increased when fat-derived neuropeptides are released.

\section{Psychological outlook}

In both young and old obese persons, pain is associated with relatively low psychosocial health when compared with persons with normal weight. ${ }^{63}$ Common characteristics in obese persons with pro-inflammatory conditions include fatigue, lethargy, social withdrawal, and irritability. ${ }^{47}$ Negative factors associated with increased prevalence of pain and multisite pain are obesity, anxiety, and depression. ${ }^{64}$ Moreover, pain symptoms are worse in obese people with the same musculoskeletal condition. For example, obese people with rheumatoid arthritis have higher pain levels, disability, and lower self-efficacy than nonobese people with rheumatoid arthritis. ${ }^{65}$

Inflammation is interconnected with negative psychological status. Hyperalgesia may be due to systemic elevations of inflammatory cytokines in the body. Variation in depression levels of obese people is explained $20 \%$ by elevated CRP. ${ }^{66}$ Anxiety and depression are directly related to circulating levels of IL-6 and CRP in obese people ${ }^{67}$ Cytokines can mediate other behavioral changes that can contribute to sedentary behavior including sadness, social-behavioral withdrawal, and anhedonia ${ }^{68}$ In obesity, there is a prolonged activation of cytokine production, which contributes to chronic pain.

Obesity is related to avoidance of physical activity, disability, and worsening of pain. ${ }^{1}$ With repeated pain exposures, catastrophizing may occur. Pain catastrophizing is an exaggerated negative orientation to harmful stimuli. ${ }^{69}$ People who catastrophize magnify the focus on pain, amplify pain sensations and experience pain that is more unpleasant, and feel helpless when pain is present. ${ }^{70}$ Morbidly obese patients with joint pain are more likely to engage in paincatastrophizing behavior. ${ }^{69,71}$ Often, catastrophizing leads to maladaptive behaviors such as activity avoidance that perpetuate continued weight gain and physical inactivity ${ }^{69,70}$ Pain catastrophizing may initiate a pathway of development 
of fear of movement (kinesiophobia) due to pain and reduce self-efficacy for performing physical tasks. ${ }^{70}$

Kinesiophobia and activity avoidance-adaptation behaviors can be triggered during daily weight-bearing activities such as walking, functional tasks, or transfers. ${ }^{72}$ It has been shown that morbidly obese adults with $\mathrm{knee}^{73}$ and chronic back pain ${ }^{63}$ experience 13\%-18\% higher fear levels compared to nonobese or less obese adults. Kinesiophobia is a predictor for ambulatory pain and perceived disability but not necessarily for physical function. ${ }^{74}$ Despite physical potential, kinesiophobia interferes with voluntary participation in regular physical activity.

\section{Exercise interventions for chronic musculoskeletal pain}

Regular exercise has been identified as primary prevention against over 35 chronic conditions including obesity, joint pain-related conditions, and anxiety and depression. Exercise stimulation can positively impact chronic pain mediators by exerting anti-inflammatory effects, ${ }^{67}$ increasing muscle strength and muscle coordination, and improving psychological outlook. ${ }^{67}$ A systematic literature search using PubMed was conducted to identify articles of exercise programs for pain in obese persons that were published between the years 1980 and 2014. The search terms "obese and chronic pain" initially resulted in 804 articles. Of these articles, it was noted that a majority of research in this population and chronic pain was associated with degenerative joint disease such as OA. Additional search terms were added to refine our article consortium such as "exercise", "musculoskeletal", "knee", "spine", "foot", "shoulder", and "elbow". Each of the articles was read by the authors to determine whether the study was relevant for this review. A total of 15 intervention studies were included in this review of the use of exercise to combat chronic pain in obese individuals (Table 1). Fourteen were exercisebased interventions for specific joint pain, and one used exercise for general musculoskeletal pain in obese persons. ${ }^{75}$ An important point is that several of these identified studies included weight management or weight loss programs that contained exercise as a main component of the program. ${ }^{76}$

Exercise programs can include resistance exercise (RX; the use of weight or resistance to overload muscle), aerobic exercise (AX; repetitive motions of large muscle groups sufficient to increase heart rate), or multimodal activities consisting of a combination of RX and AX modes. A substantial amount of evidence exists, evaluating the effectiveness of RXs and AXs to treat and reduce pain in obese individuals with $\mathrm{OA}^{2,77-83}$ and other forms of chronic pain. ${ }^{19,32,79}$ However, the literature addressing chronic pain in obesity itself is limited. Most of the research has focused on exercise treatment of one painful musculoskeletal area or joint. The following sections present the use of exercise and physical activity to combat chronic pain in this population. Table 1 provides a summary of the effects of exercise programs on musculoskeletal pain symptoms in obese individuals.

\section{Exercise for chronic LBP}

Of the estimated 34 million Americans suffering from chronic LBP, $64.3 \%$ of respondents were overweight or obese. ${ }^{84}$ It has also been reported that chronic LBP in the obese population is a significant contributor to fear avoidance behaviors and further increases in functional disability. ${ }^{85}$ Therefore, reducing pain associated with LBP in obese persons can stunt the vicious pain disabling and weight gain cycle experienced by obese individuals.

Two recent analyses were performed that compared different resistance protocols for chronic LBP in obese persons. ${ }^{86,87}$ Abdominally obese adults aged 6-85 years with chronic LBP were randomized to total body resistance (TOTRX; ten upper and lower body RXs and lumbar extension), isolated lumbar extension exercise (LEXT; participants performed lumbar extension only), or the non-exercise control group (CON). All participants received the standard of care, pamphlets, and education materials on physical activity guidelines and weight loss benefits. ${ }^{86}$ Resting and pain with activity were measured during walking, stair climbing, and chair rise. Greater reductions in resting average back pain levels ${ }^{87}$ and walking pain were achieved with TOTRX and LEXT compared to CON (60.5\% and $42.0 \%$ vs $6.4 \%$, respectively). ${ }^{86}$ Pain with chair rise was decreased by $49.8 \%$ in TOTRX group compared to the other groups (3.7\% and $0.3 \%$ reduction). ${ }^{86}$ Pain during functional tasks was also significantly decreased in the TOTRX group compared to the others. ${ }^{86}$ In these studies, participants did not lose weight despite pain relief. Subsequent studies should focus on whether or not there is additive pain relief with exercise and weight loss compared to each individually.

Based on our search of the literature, there were no other studies examining the effects of exercise to reduce LBP in obese individuals. Minimal evidence exists supporting the use of back extension exercises in the general population with LBP. ${ }^{88}$ However, the data presented above combined with previously accepted protocols for therapeutic interventions in LBP are encouraging and suggest that RXs combined with targeted back extension exercises can significantly reduce pain in the obese individual safely and effectively while minimizing 


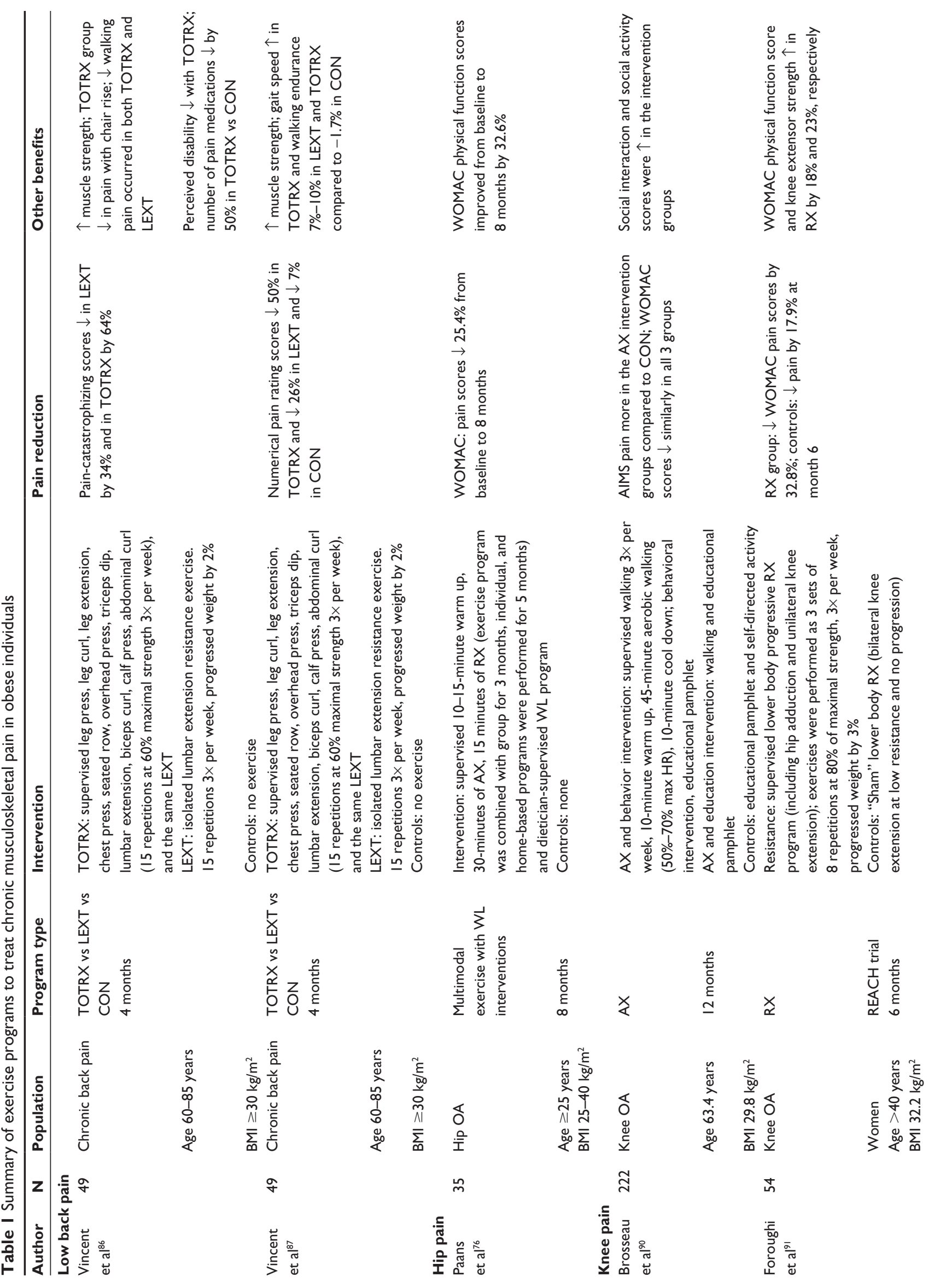



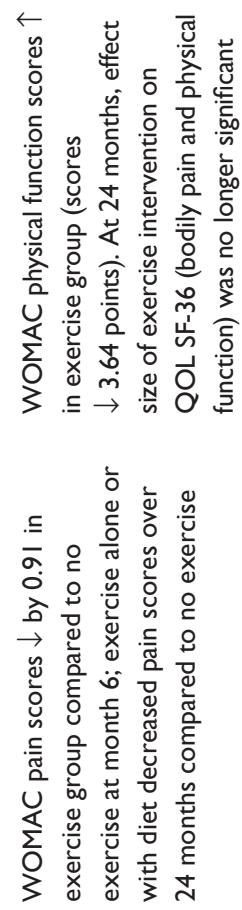
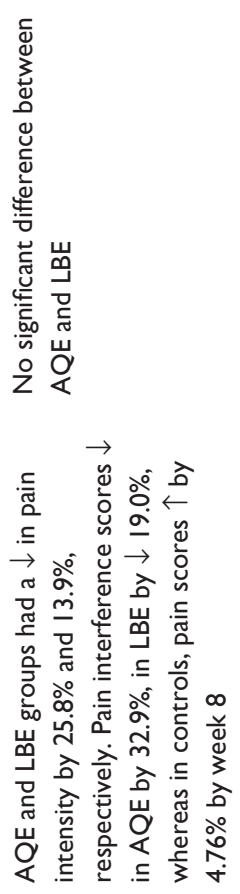
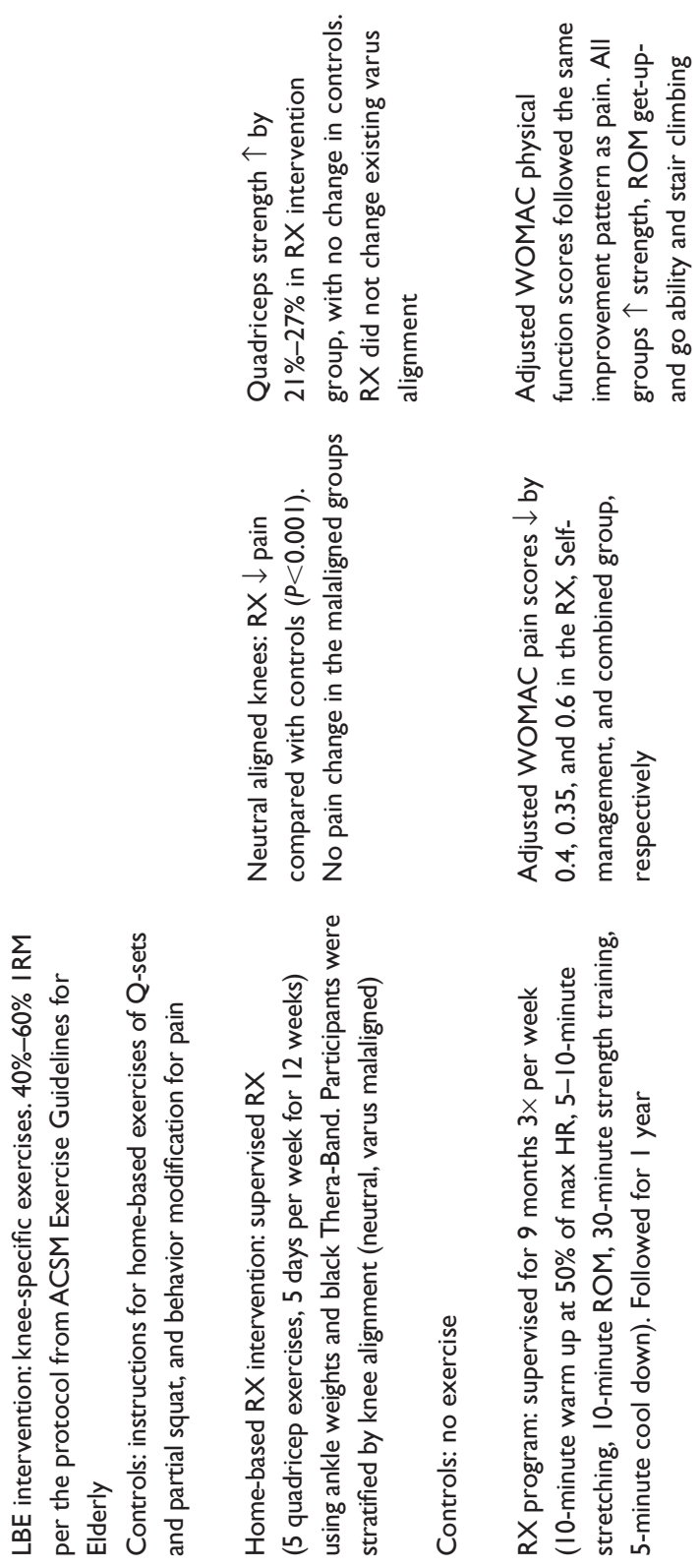
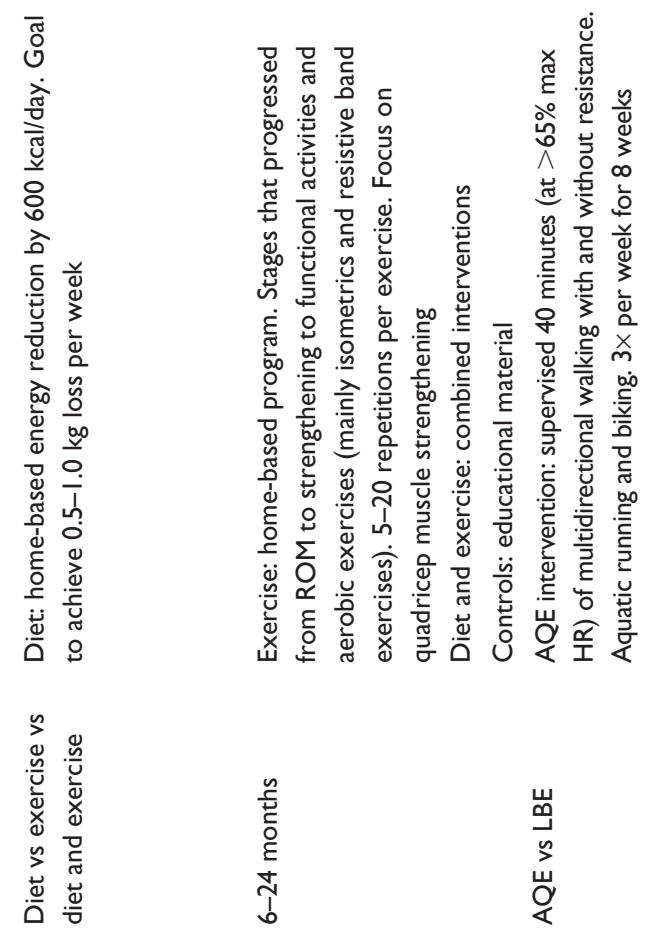

$\stackrel{u}{9}$
$\stackrel{n}{山}$
$\stackrel{0}{\alpha}$
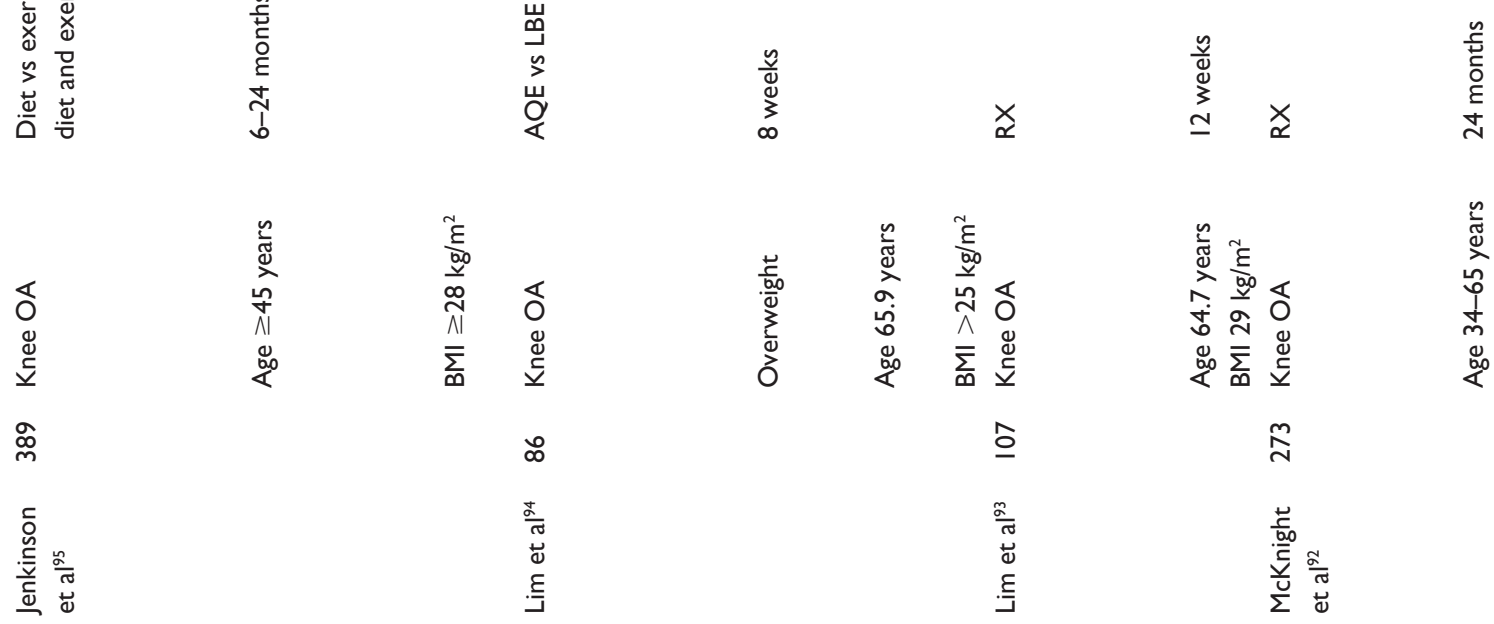

$\underset{x}{x}$

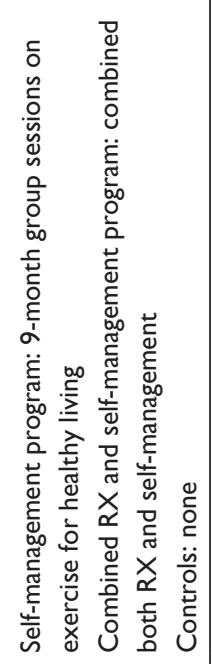

œ

으

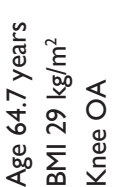

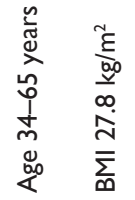

กิ

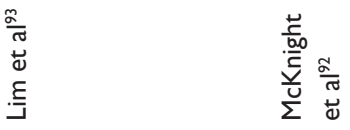




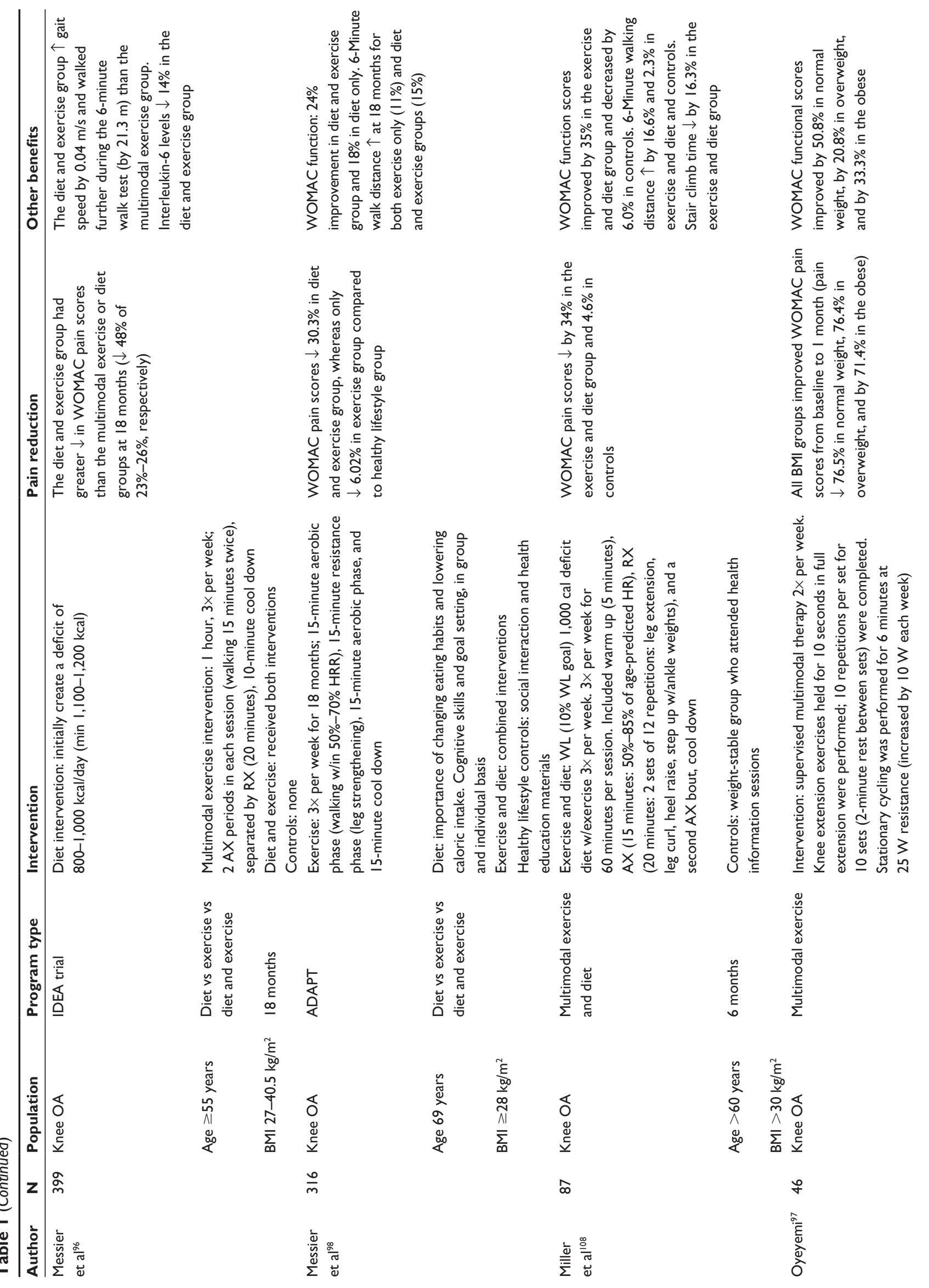



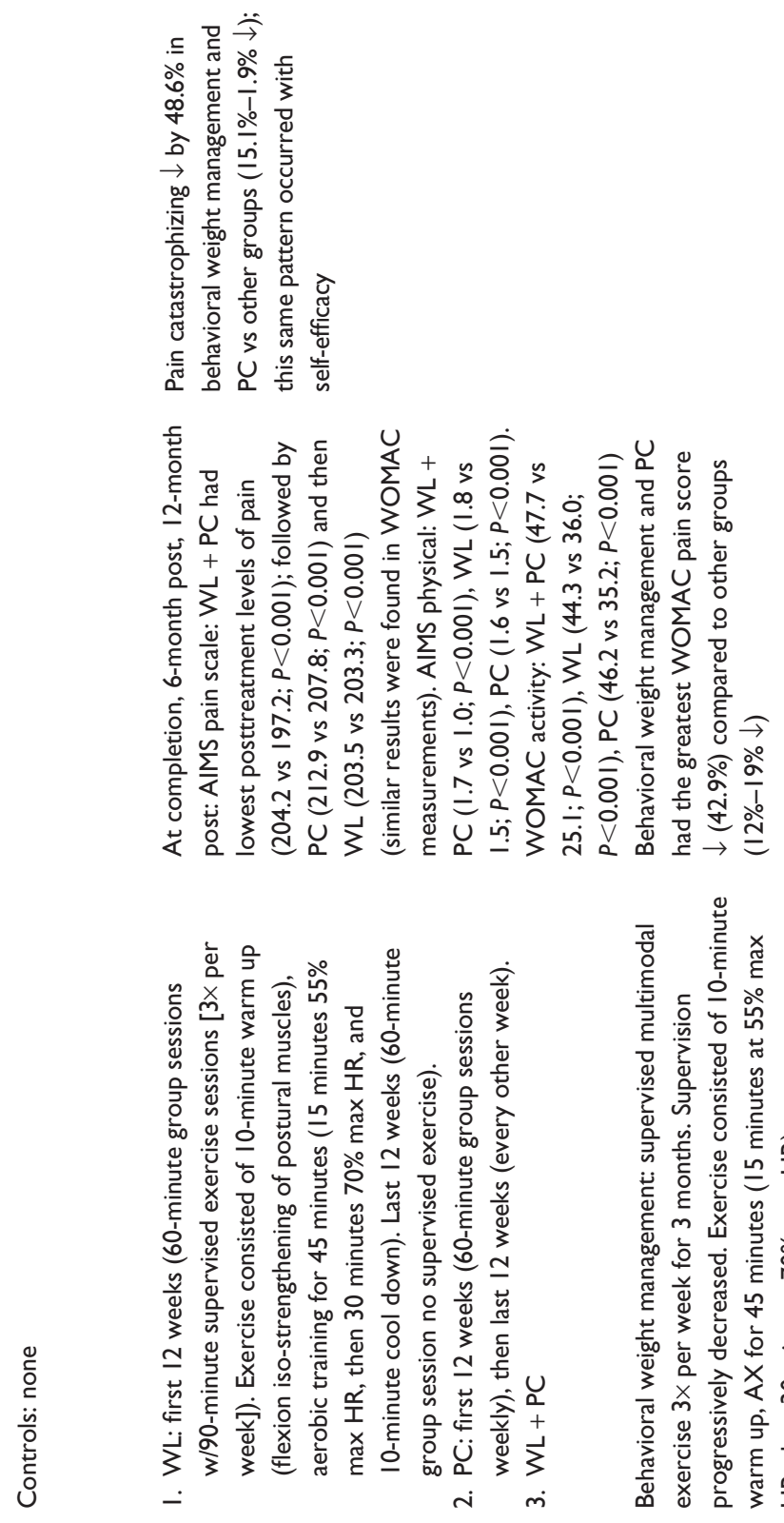

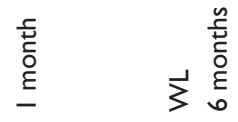

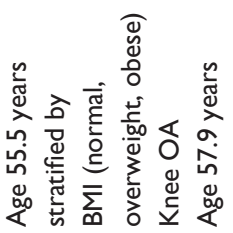

กี

है

(1)
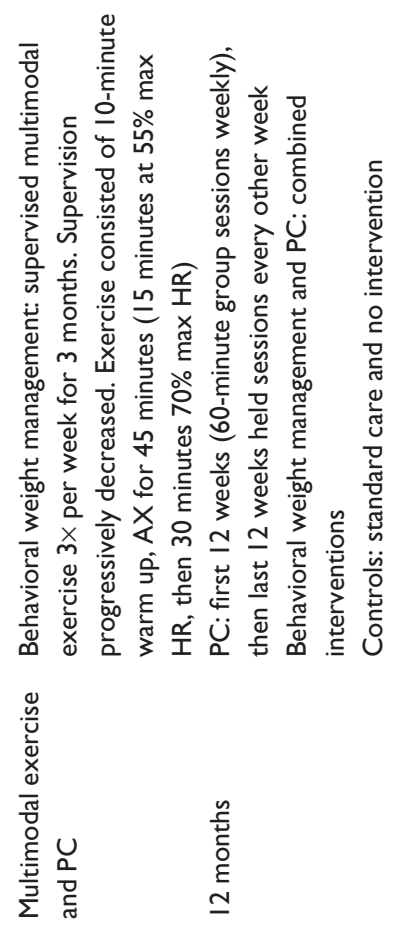

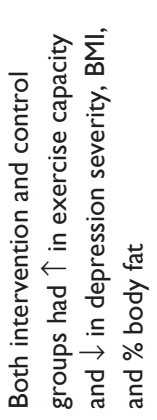

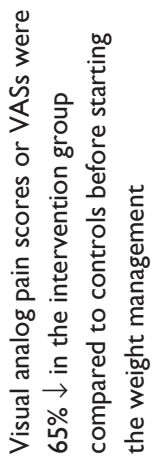
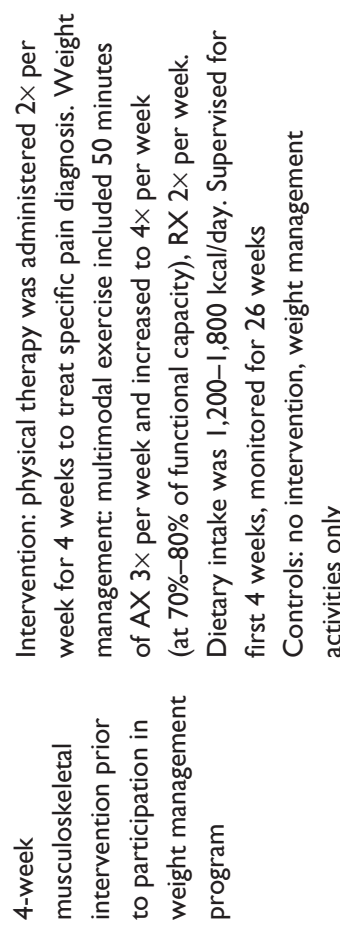

穿它

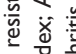

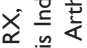

的部占

×

능

离离走

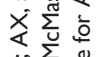

논 은

ญั О

० 矛

03 范

它发

기엉

के

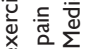

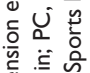

茂喜和

है

专旁

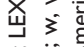

过论定

莺黄㣢

ते

의

퓽 흔

x ํํำ

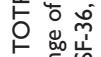

过

ญ

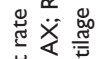

苋可

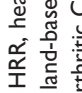

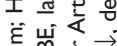

है

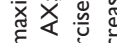

ᄃ

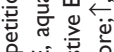

造岁旁

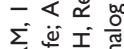

壬志

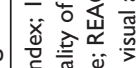

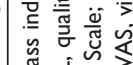

更

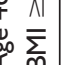

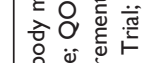

产

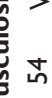

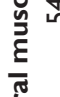

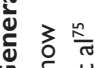

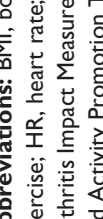


pain medication use. ${ }^{86}$ Importantly, additional benefits of RX for LBP include a significant reduction in perceived disability due to pain as shown by improved Roland Morris Disability and Oswestry Disability Index scores, significantly lower pain catastrophizing, ${ }^{86}$ and faster gait speed ${ }^{87}$ When back strength increased more than $20 \%$ from baseline, pain levels improved more than if back strength did not increase more than $20 \%$ with either TOTRX or LEXT. ${ }^{87}$ From the functional perspective, lumbar strength gains are related to walking endurance improvements. The collective benefits of RX for chronic LBP in obesity may translate to a better quality of life and interest in additional healthy lifestyle behaviors in this population. Long-term studies can address this issue.

\section{Exercise for chronic hip pain}

Limited evidence exists specifically targeting exercises for chronic hip pain ${ }^{82}$ in obese persons. There are presently no randomized controlled trials examining the effects of using exercise for reducing OA-related hip pain in the general population. ${ }^{82}$ To our knowledge, one intervention study investigated the exercise effects on hip pain reduction in obese persons. ${ }^{76}$ Paans et al ${ }^{76}$ combined an 8-month multimodal exercise program with dietary weight loss to combat hip pain and physical function in obese persons. The exercise program consisted of moderate-to-intense AX (treadmill, bike, stepper, rowing machines) and RX. ${ }^{76}$ All participants received the same intervention, but specifics were modified to accommodate individual needs and abilities. There was no control group; participants were compared to their baseline scores to assess improvements. Significant improvements were observed at the 8-month follow-up for both pain and functional abilities based on the Western Ontario McMaster Osteoarthritis Index (WOMAC) and Medical Outcomes Short Form 36 (SF-36). ${ }^{76}$ Pain domains of the WOMAC and the SF-36 decreased by $36.6 \%$ and $25.4 \%$, respectively. ${ }^{76}$ Other benefits for hip pain included $32.6 \%-47.1 \%$ improvements in perceived physical function as on the WOMAC and SF-36, respectively. ${ }^{76}$ Walking mobility improved by $11.1 \%$ at 8 -month follow-up. ${ }^{76}$ These results are promising, but due to the lack of a control group and separate analysis of exercise vs weight loss alone, further evidence is needed to definitively state the effects of exercise reducing pain in obese individuals with hip OA. Further research is warranted to understand the specific mechanisms of pain relief in hip OA.

\section{Exercise interventions for chronic knee pain}

Approximately 60 million Americans have knee $\mathrm{OA},{ }^{2}$ and about $10 \%-30 \%$ of these individuals have such severe pain that their functional ability is restricted leading to disability. ${ }^{2}$ The addition of a BMI $\geq 30 \mathrm{~kg} / \mathrm{m}^{2}$ increases the risk of developing knee OA fourfold compared to healthy weight individuals. ${ }^{89}$ Chronic knee pain perpetuates activity avoidance and additional weight gain. Hence, preventing and/or restoring functional capacity while mitigating pain in obese patients is critical for prolonged adherence to exercise programs.

Both $\mathrm{AX}^{90}$ and $\mathrm{RX}^{91-93}$ programs of varying duration from 2 months to 24 months can significantly reduce knee pain. AX-based interventions used walking ${ }^{90}$ or aquatic runningcycling exercise ${ }^{94}$ as the primary stimulus. Aquatic exercise appears to confer rapid knee pain relief within 2 months compared to walking over a 12-month duration. RX-based programs have used low resistance weights, therapy bands, or pneumatic machines to induce pain relief. ${ }^{91-93,95}$ While AX activates muscles about the knee in a linear anteroposterior direction, RX activates multiple muscle groups about the knee and in joints above and below the knee to improve strength across different planes of motion. RX may act by correcting muscle strength deficits and knee instability, thereby allowing the affected individual to engage in more activity with less pain. ${ }^{95}$ One report showed that pain relief may be greater in people who have neutral knee alignment compared to varus alignment, ${ }^{93}$ suggesting that other treatments such as bracing may increase effectiveness of RX on pain relief. Supervised and home-based programs are effective in increasing quadriceps strength and reducing pain over the long term. ${ }^{95}$

Multimodal exercise programs have been used alone or combined with other treatments such as dietary modification, weight loss, or pain-coping skills training to treat knee pain. ${ }^{71,96,97}$ Both $\mathrm{AX}$ and RX activities are combined together during single-exercise sessions in alternating or sequential fashion. Exercise is important for long-term maintenance of mobility and walking endurance. ${ }^{98}$ Pain severity, inflammatory cytokine levels such as IL-6, and body weight are lowered more with exercise and dietary modification compared to either treatment alone. ${ }^{96,98}$ One study examined the independent and combined effects of multimodal exercise and pain-coping skill training on pain and functional outcomes in obese people with knee OA over 6 months. ${ }^{71}$ The combined treatments were superior with respect to producing greater reductions in self-reported pain, physical function, joint stiffness, pain catastrophizing, and greater improvements in self-efficacy and psychological outlook than each treatment alone. ${ }^{71}$ The use of multimodal exercise for pain relief is effective for knee pain in obese people, but exercise benefits may be enhanced with the addition of dietary restriction or pain-coping skills. 


\section{Exercise for generalized \\ or whole body pain}

Presently, there is limited research assessing the effects of exercise on generalized pain in obesity. One investigation was designed to test the use of a "musculoskeletal pain physical therapy program" prior to entering a weight management program.${ }^{75}$ The weight management protocol included daily caloric restriction to $1,200-1,800 \mathrm{kcal} /$ day and multimodal exercise (AX three times per week, RX two times per week). Snow et $\mathrm{al}^{75}$ reported that patients who received the intervention had a reduction in mean bodily pain by $56 \%$ prior to participation. During the weight management phase, the intervention and control groups experienced similar weight loss, depression scores, and exercise capacity. ${ }^{75}$ In contrast to expectations, the intervention group did not demonstrate greater weight loss or ability to exercise at higher intensities. It is possible that the participants achieved their goal of pain reduction and perceived that the intervention was a success. Additional research could examine what biochemical or psychobiological factors may be favorably altered by therapy programs or different exercise programs. This information could help practitioners and therapists determine the best exercise strategy to manage pain in obese patients.

\section{Mechanisms of exercise improvement of musculoskeletal pain}

Figure 2 summarizes the potential exercise-related mechanisms underlying pain in children and adults. Each positive change in one mechanism favorably contributes to the others. Reductions in body weight with AX can reduce mechanical loading and structural damage to the weight-bearing joints and tissues, ${ }^{2}$ thereby reducing the inflammatory response to

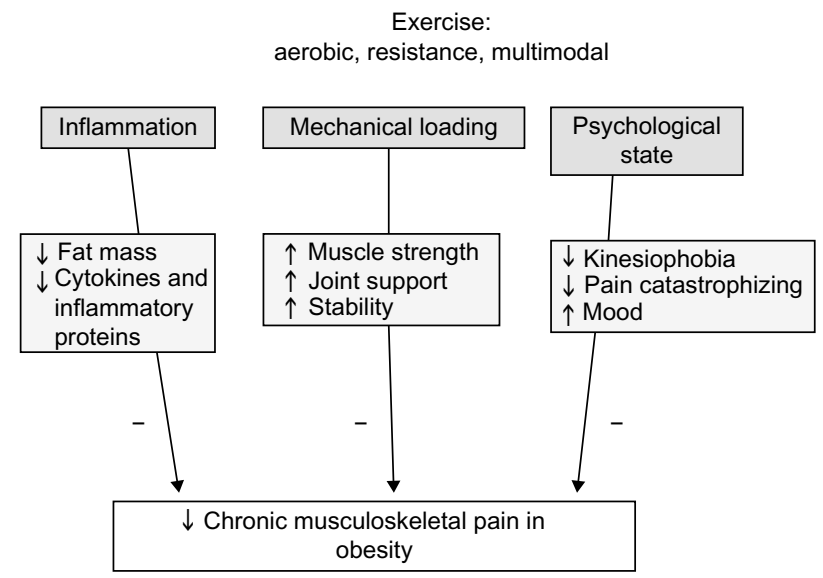

Figure 2 Effects of exercise on inflammation, mechanical and psychological state on musculoskeletal pain in obesity

Notes: ; $\uparrow$, increase; $\downarrow$, decrease; - denotes a decrease effect. damage. RX corrects strength deficits around painful joints and may help restore normal joint kinematics. Reduction of visceral, subcutaneous, and local body fat volumes with AX lowers the production of circulating pro-inflammatory cytokines and proteins. ${ }^{99}$ Regular participation in highintensity intermittent physical activity lowers systemic levels of inflammatory cytokines (CRP, IL-6, and TNF- $\alpha$ ), but the greatest anti-inflammatory benefit occurs with the multimodal exercise. ${ }^{100} \mathrm{RX}$ increases self-efficacy and reduces depression symptoms, ${ }^{1}$ which lower stress and HPA activity. Total mood disturbance is attenuated, and several psychosocial domains such as tension, anger, vigor, fatigue body areas satisfaction, and physical self-concept are significantly improved with supervised exercise. ${ }^{101}$ These positive changes enhance stress reduction and complement physical adaptations to exercise that collectively contribute to pain relief in obese persons. Future studies can examine whether there are "responders" to exercise who are able to make better improvements in specific mechanisms and thereby experience better pain relief than "nonresponders".

\section{Solutions for increasing exercise adherence in obese individuals}

The American College of Sports Medicine, ${ }^{102}$ the American Dietetic Association, ${ }^{103}$ and the American Heart Association ${ }^{104}$ provide evidence-based recommendations for physical activity prescriptions for significant weight loss and maintenance. However, adherence to exercise is a challenge for obese persons, as shown by attrition rates ranging from $43.5 \%$ (children) ${ }^{105}$ and 50\% (adults). ${ }^{101}$ There are several possible solutions to help improve adherence and increase the enjoyment of exercise and physical activity. First, tailoring exercise programs to accommodate the needs and abilities of obese individuals is recommended. ${ }^{106}$ Modifications to the specific exercises may be necessary to offset the acute pain with mechanical loading. For example, RXs can be performed within the non-painful range of motion (reduce the overall motion of the knee extension or flexion exercise). Second, walking or running can be painful for obese persons, but incline walking at slower speeds is less painful or not painful, ${ }^{107}$ which fosters adherence. As weight is reduced ${ }^{108}$ or pain improves, speed, duration, and frequency of AX can increase. Third, on days when musculoskeletal pain flares occur, the use of nonimpact exercise may be more comfortable than impact exercise. Examples of this include aquatic treadmill, cycle or pool exercise classes, elliptical machines, or Nordic ski machines. Fourth, sustained or continuous exercise may be more uncomfortable than several smaller exercise bouts ${ }^{109}$ to accumulate the cardiovascular or strength stimulus 
necessary to accumulate benefit and pain relief. Longer bouts of sustained low- or moderate-intensity exercise may prolong pain, but shorter more intense exercise may decrease the load-bearing exposure time. Fifth, the exercise program should not progress more than $5 \%-10 \%$ of weekly mileage or duration. This threshold has been proposed to permit bone tissues to "rest" and avoid mechanical failure. ${ }^{109}$ Studies that determine the reasons for obese persons failing to maintain exercise levels with or without pain relief would help practitioners identify obese patients who may need additional interventions to promote adherence.

For individuals experiencing pain too disabling for regular movement, pain reduction is paramount for breaking the cycle of pain-related inhibition of exercise. Depending on the location of the pain and the severity, several medications may be used to reduce pain to make exercise more tolerable. For example, nonsteroidal anti-inflammatory medications such as ibuprofen, naproxen, or aspirin can help control inflammatory processes associated with obesity and pain severity. Procedural treatments such as intra-articular injections of corticosteroids and hyaluronic acid preparations into the knee, hip, or shoulder may be used for immediate and longterm pain relief, thereby allowing the individual to exercise, burn calories, and improve function. ${ }^{1}$

Exercise-induced joint pain should not persist or increase by 24 hours after exercise, which is an indication that the musculoskeletal system was not prepared for the exercise, or physical days will permit the individual to make a selfassessment of the pain response. ${ }^{109}$ If an obese person with preexisting mild joint pain starts activity ( $<3$ points out of a 10-point scale), similar guidelines apply: the pain should not worsen during the exercise session or last into the next day. If the pain causes a limp or a compensatory gait change, the exercise volume must be reduced, or the exercise must be stopped until a normal gait pattern is achieved. It has been suggested that strengthening exercise or RX be initiated prior to starting a formal AX program to help develop muscle strength, joint support, and stability. ${ }^{109}$ Control of exercise pain and functional ability may foster enjoyment of exercise and better adherence.

\section{Conclusion}

Obesity is associated with general and specific musculoskeletal pain. There is an interrelationship between mechanical loading, chronic pain, inflammation, and psychological status in obese persons. AX, RX, or multimodal exercise programs can reduce joint pain in young and older obese adults in the range of $14 \%-71.4 \%$ via one or more of these three potential mechanisms. While adherence to regular exercise is low, several methods to increase adherence include modification of exercise including splitting up exercise duration into smaller bouts, reducing joint range of motion, and minimizing impact activity. Additional research is necessary to determine the following: 1) if there are characteristics of responders to exercise that favor weight loss and long-term pain relief; 2) if there are additive effects of exercise and weight loss on musculoskeletal pain severity; and 3) if the quality of life can be improved with exercise-induced pain relief. This field would benefit from rigorous comparative efficacy studies of exercise intensity, frequency, and mode on specific and general musculoskeletal pain in young and older obese persons.

\section{Disclosure}

The authors report no conflicts of interest in this work.

\section{References}

1. Vincent HK, Adams MCB, Vincent KR, Hurley RW. Musculoskeletal pain, fear avoidance behaviors, and functional decline in obesity: potential interventions to manage pain and maintain function. Reg Anesth Pain Med. 2013;38(6):481-491.

2. Vincent KR, Vincent HK. Resistance exercise for knee osteoarthritis. PM R. 2012;4(5 Suppl):S45-S52.

3. Andersen RE, Crespo CJ, Bartlett SJ, Bathon JM, Fontaine KR. Relationship between body weight gain and significant knee, hip, and back pain in older Americans. Obes Res. 2003;11(10):1159-1162.

4. Heo M, Allison DB, Faith MS, Zhu S, Fontaine KR. Obesity and quality of life: mediating effects of pain and comorbidities. Obes Res. 2003;11(2):209-216.

5. Anandacoomarasamy A, Caterson ID, Leibman S, et al. Influence of BMI on health-related quality of life: comparison between an obese adult cohort and age-matched population norms. Obesity. 2009;17(11): 2114-2118.

6. Smith SM, Sumar B, Dixon KA. Musculoskeletal pain in overweight and obese children. Int J Obes. 2014;38(1):11-15.

7. Johnson NB, Hayes LD, Brown K, Hoo EC, Ethier KA. CDC National Health Report: leading Causes of Morbidity and Mortality and Associated Behavioral Risk and Protective Factors-United States, 2005-2013. MMWR Surveill Summ. 2014;63:3-27.

8. Glass NA, Torner JC, Frey Law LA, et al. The relationship between quadriceps muscle weakness and worsening of knee pain in the MOST cohort: a 5-year longitudinal study. Osteoarthr Cartil. 2013;21(9): $1154-1159$.

9. Yoo JJ, Lim SH, Cho NH, Kim HA. Relationships between body mass index, fat mass, muscle mass, and musculoskeletal pain in community residents. Arthritis Rheumatol. 2014;66(12):3511-3520.

10. Nilsen TIL, Holtermann A, Mork PJ. Physical exercise, body mass index, and risk of chronic pain in the low back and neck/shoulders: longitudinal data from the Nord-Trøndelag health study. Am J Epidemiol. 2011;174(3):267-273.

11. De Sá Pinto AL, De Barros Holanda PM, Radu AS, Villares SM, Lima FR. Musculoskeletal findings in obese children. J Paediatr Child Health. 2006;42(6):341-344.

12. Hannibal KE, Bishop MD. Chronic stress, cortisol dysfunction, and pain: a psychoneuroendocrine rationale for stress management in pain rehabilitation. Phys Ther. 2014;94(12):1816-1825.

13. Egan AM, Mahmood WA, Fenton R, et al. Barriers to exercise in obese patients with type 2 diabetes. QJM. 2013;106(7):635-638. 
14. Groven KS, Engelsrud G. Dilemmas in the process of weight reduction: exploring how women experience training as a means of losing weight. Int J Qual Stud Health Well-Being. 2010;22:5.

15. Sallinen J, Leinonen R, Hirvensalo M, Lyyra T-M, Heikkinen E, Rantanen T. Perceived constraints on physical exercise among obese and non-obese older people. Prev Med. 2009;49(6):506-510.

16. Shelby RA, Somers TJ, Keefe FJ, Pells JJ, Dixon KE, Blumenthal JA. Domain specific self-efficacy mediates the impact of pain catastrophizing on pain and disability in overweight and obese osteoarthritis patients J Pain. 2008;9(10):912-919.

17. Lementowski PW, Zelicof SB. Obesity and osteoarthritis. Am J Orthop. 2008;37(3):148-151.

18. Grotle M, Hagen KB, Natvig B, Dahl FA, Kvien TK. Obesity and osteoarthritis in knee, hip and/or hand: an epidemiological study in the general population with 10 years follow-up. BMC Musculoskelet Disord. 2008;9:132.

19. Deere KC, Clinch J, Holliday K, et al. Obesity is a risk factor for musculoskeletal pain in adolescents: findings from a population-based cohort. Pain. 2012;153(9):1932-1938.

20. Gay A, Culliford D, Leyland K, Arden NK, Bowen CJ. Associations between body mass index and foot joint pain in middle-aged and older women: a longitudinal population-based cohort study. Arthritis Care Res. 2014;66(12):1873-1879.

21. Jentzsch T, Geiger J, Slankamenac K, Werner CML. Obesity measured by outer abdominal fat may cause facet joint arthritis at the lumbar spine. J Back Musculoskelet Rehabil. Epub 2014 Jun 24.

22. Fowler-Brown A, Wee CC, Marcantonio E, Ngo L, Leveille S. The mediating effect of chronic pain on the relationship between obesity and physical function and disability in older adults. J Am Geriatr Soc 2013;61(12):2079-2086.

23. Hitt HC, McMillen RC, Thornton-Neaves T, Koch K, Cosby AG. Comorbidity of obesity and pain in a general population: results from the southern pain prevalence study. J Pain. 2007;8(5):430-436.

24. Zhang W, McWilliams DF, Ingham SL, et al. Nottingham knee osteoarthritis risk prediction models. Ann Rheum Dis. 2011;70(9): 1599-1604.

25. Pain H, Wiles R. The experience of being disabled and obese. Disabil Rehabil. 2006;28(19):1211-1220.

26. Vincent HK, Raiser SN, Vincent KR. The aging musculoskeletal system and obesity-related considerations with exercise. Ageing Res Rev. 2012;11(3):361-373.

27. Evers Larsson U, Mattsson E. Functional limitations linked to high body mass index, age and current pain in obese women. Int $J$ Obes Relat Metab Disord. 2001;25(6):893-899.

28. Garver MJ, Focht BC, Dials J, et al. Weight status and differences in mobility performance, pain symptoms, and physical activity in older, knee osteoarthritis patients. Arthritis. 2014;2014:375909.

29. Rimmer JH, Hsieh K, Graham BC, Gerber BS, Gray-Stanley JA. Barrier removal in increasing physical activity levels in obese African American women with disabilities. J Womens Health. 2010;19(10):1869-1876.

30. Centers for Disease Control and Prevention (CDC). Arthritis as a potential barrier to physical activity among adults with obesity United States, 2007 and 2009. MMWR Morb Mortal Wkly Rep. 2011; 60(19):614-618.

31. Ball K, Crawford D, Owen N. Too fat to exercise? Obesity as a barrier to physical activity. Aust N Z J Public Health. 2000;24(3):331-333.

32. Atchison JW, Vincent HK. Obesity and low back pain: relationships and treatment. Pain Manag. 2012;2(1):79-86.

33. Tsuritani I, Honda R, Noborisaka Y, Ishida M, Ishizaki M, Yamada Y. Impact of obesity on musculoskeletal pain and difficulty of daily movements in Japanese middle-aged women. Maturitas. 2002;42(1): 23-30.

34. Sharkey JR, Ory MG, Branch LG. Severe elder obesity and 1-year diminished lower extremity physical performance in homebound older adults. J Am Geriatr Soc. 2006;54(9):1407-1413.

35. Viton J-M, Timsit M, Mesure S, Massion J, Franceschi J-P, Delarque A Asymmetry of gait initiation in patients with unilateral knee arthritis. Arch Phys Med Rehabil. 2000;81(2):194-200.
36. Constantinou M, Barrett R, Brown M, Mills P. Spatial-temporal gait characteristics in individuals with hip osteoarthritis: a systematic literature review and meta-analysis. J Orthop Sports Phys Ther. 2014;44(4): 291-B7.

37. Hills AP, Parker AW. Gait characteristics of obese children. Arch Phys Med Rehabil. 1991;72(6):403-407.

38. Andriacchi TP, Favre J. The nature of in vivo mechanical signals that influence cartilage health and progression to knee osteoarthritis. Curr Rheumatol Rep. 2014;16(11):463.

39. Mills K, Hettinga BA, Pohl MB, Ferber R. Between-limb kinematic asymmetry during gait in unilateral and bilateral mild to moderate knee osteoarthritis. Arch Phys Med Rehabil. 2013;94(11):2241-2247.

40. Eitzen I, Fernandes L, Nordsletten L, Snyder-Mackler L, Risberg MA. Weight-bearing asymmetries during Sit-To-Stand in patients with mildto-moderate hip osteoarthritis. Gait Posture. 2014;39(2):683-688.

41. Marks R. Obesity profiles with knee osteoarthritis: correlation with pain, disability, disease progression. Obesity. 2007;15(7):1867-1874.

42. Butterworth PA, Urquhart DM, Cicuttini FM, et al. Fat mass is a predictor of incident foot pain. Obesity. 2013;21(9):E495-E499.

43. Messier SP, Gutekunst DJ, Davis C, DeVita P. Weight loss reduces knee-joint loads in overweight and obese older adults with knee osteoarthritis. Arthritis Rheum. 2005;52(7):2026-2032.

44. Kaur J. A comprehensive review on metabolic syndrome. Cardiol Res Pract. 2014;2014:943162.

45. Marcus DA. Obesity and the impact of chronic pain. Clin J Pain. 2004;20(3):186-191.

46. Cesari M, Kritchevsky SB, Baumgartner RN, et al. Sarcopenia, obesity, and inflammation - results from the Trial of Angiotensin Converting Enzyme Inhibition and Novel Cardiovascular Risk Factors study. Am J Clin Nutr. 2005;82(2):428-434.

47. Seaman DR. Body mass index and musculoskeletal pain: is there a connection? Chiropr Man Therap. 2013;21:15.

48. Paradowski PT, Englund M, Lohmander LS, Roos EM. The effect of patient characteristics on variability in pain and function over two years in early knee osteoarthritis. Health Qual Life Outcomes. 2005;3:59.

49. Messier SP, Pater M, Beavers DP, et al. Influences of alignment and obesity on knee joint loading in osteoarthritic gait. Osteoarthritis Cartilage. 2014;22(7):912-917.

50. Monteiro M, Gabriel R, Aranha J, Neves e Castro M, Sousa M, Moreira M. Influence of obesity and sarcopenic obesity on plantar pressure of postmenopausal women. Clin Biomech. 2010;25(5):461-467.

51. Fabris SM, Faintuch J, Brienze SL, et al. Are knee and foot orthopedic problems more disabling in the superobese? Obes Surg. 2013;23(2): 201-204.

52. Andriacchi TP, Mündermann A, Smith RL, Alexander EJ, Dyrby CO, Koo S. A framework for the in vivo pathomechanics of osteoarthritis at the knee. Ann Biomed Eng. 2004;32(3):447-457.

53. Menegoni F, Galli M, Tacchini E, Vismara L, Cavigioli M, Capodaglio P. Gender-specific effect of obesity on balance. Obesity. 2009;17(10): 1951-1956.

54. Gupta M, Dashottar A, Borstad JD. Scapula kinematics differ by body mass index. J Appl Biomech. 2013;29(4):380-385.

55. Samartzis D, Karppinen J, Cheung J, Lotz J. Disk degeneration and low back pain: are they fat-related conditions? Global Spine J. 2013;03(03):133-144

56. Galli MM, Protzman NM, Mandelker EM, Malhotra A, Schwartz E, Brigido SA. Comparing tendinous and ligamentous ankle pathology in atraumatic overweight and nonoverweight patients: a comprehensive MRI review. Foot Ankle Spec. 2014;7(6):449-456.

57. Irwin MR. Inflammation at the intersection of behavior and somatic symptoms. Psychiatr Clin North Am. 2011;34(3):605-620.

58. Arranz L-I, Rafecas M, Alegre C. Effects of obesity on function and quality of life in chronic pain conditions. Curr Rheumatol Rep. 2014; 16(1):1-8.

59. Briggs MS, Givens DL, Schmitt LC, Taylor CA. Relations of C-reactive protein and obesity to the prevalence and the odds of reporting low back pain. Arch Phys Med Rehabil. 2013;94(4):745-752. 
60. Bas S, Finckh A, Puskas GJ, et al. Adipokines correlate with pain in lower limb osteoarthritis: different associations in hip and knee. Int Orthop. 2014;38(12):2577-2583.

61. Sokolove J, Lepus CM. Role of inflammation in the pathogenesis of osteoarthritis: latest findings and interpretations. Ther Adv Musculoskelet Dis. 2013;5(2):77-94.

62. Goldring MB, Otero M. Inflammation in osteoarthritis. Curr Opin Rheumatol. 2011;23(5):471-478.

63. Vincent HK, Omli MR, Day T, Hodges M, Vincent KR, George SZ. Fear of movement, quality of life, and self-reported disability in obese patients with chronic lumbar pain. Pain Med. 2011;12(1):154-164.

64. Hoftun GB, Romundstad PR, Rygg M. Factors associated with adolescent chronic non-specific pain, chronic multisite pain, and chronic pain with high disability: the Young-HUNT Study 2008. J Pain. 2012;13(9):874-883.

65. Somers TJ, Wren AA, Blumenthal JA, Caldwell D, Huffman KM, Keefe FJ. Pain, physical functioning, and overeating in obese rheumatoid arthritis patients: do thoughts about pain and eating matter? J Clin Rheumatol. 2014;20(5):244-250.

66. Daly M. The relationship of C-reactive protein to obesity-related depressive symptoms: a longitudinal study. Obesity (Silver Spring). 2013;21(2):248-250.

67. Capuron L, Poitou C, Machaux-Tholliez D, et al. Relationship between adiposity, emotional status and eating behaviour in obese women: role of inflammation. Psychol Med. 2011;41(7):1517-1528.

68. Slavich GM, Irwin MR. From stress to inflammation and major depressive disorder: a social signal transduction theory of depression. Psychol Bull. 2014;140(3):774-815.

69. Somers TJ, Keefe FJ, Pells JJ, et al. Pain catastrophizing and painrelated fear in osteoarthritis patients: relationships to pain and disability. J Pain Symptom Manage. 2009;37(5):863-872.

70. Somers TJ, Keefe FJ, Carson JW, Pells JJ, LaCaille L. Pain catastrophizing in borderline morbidly obese and morbidly obese individuals with osteoarthritic knee pain. Pain Res Manag. 2008;13(5):401-406.

71. Somers TJ, Blumenthal JA, Guilak F, et al. Pain coping skills training and lifestyle behavioral weight management in patients with knee osteoarthritis: a randomized controlled study. Pain. 2012;153(6): 1199-1209.

72. Gooberman-Hill R, Woolhead G, MacKichan F, Ayis S, Williams S, Dieppe P. Assessing chronic joint pain: lessons from a focus group study. Arthritis Care Res. 2007;57(4):666-671.

73. Vincent HK, Lamb KM, Day TI, Tillman SM, Vincent KR, George SZ. Morbid obesity is associated with fear of movement and lower quality of life in patients with knee pain-related diagnoses. PM R. 2010;2(8): 713-722.

74. Vincent HK, Seay AN, Montero C, Conrad BP, Hurley RW, Vincent KR. Kinesiophobia and fear-avoidance beliefs in overweight older adults with chronic low-back pain: relationship to walking endurance-part II. Am J Phys Med Rehabil. 2013;92(5):439-445.

75. Snow R, Ruane J, LaLonde M, et al. Randomized trial assessing the impact of a musculoskeletal intervention for pain before participating in a weight management program. [Miscellaneous Article]. J Cardiopulm Rehabil Prev. 2010;30(3):173-180.

76. Paans N, van den Akker-Scheek I, Dilling RG, et al. Effect of exercise and weight loss in people who have hip osteoarthritis and are overweight or obese: a prospective cohort study. Phys Ther. 2013;93(2): 137-146.

77. Doi T, Akai M, Fujino K, et al. Effect of home exercise of quadriceps on knee osteoarthritis compared with nonsteroidal antiinflammatory drugs: a randomized controlled trial. Am J Phys Med Rehabil. 2008;87(4): 258-269.

78. Escalante Y, García-Hermoso A, Saavedra JM. Effects of exercise on functional aerobic capacity in lower limb osteoarthritis: a systematic review. J Sci Med Sport. 2011;14(3):190-198.

79. Escalante Y, Saavedra JM, García-Hermoso A, Silva AJ, Barbosa TM. Physical exercise and reduction of pain in adults with lower limb osteoarthritis: a systematic review. J Back Musculoskelet Rehabil. 2010; 23(4):175-186.
80. Ettinger WH Jr, Burns R, Messier SP, et al. A randomized trial comparing aerobic exercise and resistance exercise with a health education program in older adults with knee osteoarthritis. The Fitness Arthritis and Seniors Trial (FAST). JAMA. 1997;277(1):25-31.

81. Farr JN, Going SB, McKnight PE, Kasle S, Cussler EC, Cornett M. Progressive resistance training improves overall physical activity levels in patients with early osteoarthritis of the knee: a randomized controlled trial. Phys Ther. 2010;90(3):356-366.

82. Fransen M, McConnell S. Exercise for osteoarthritis of the knee. Cochrane Database Syst Rev. 2008;(4):CD004376.

83. Fransen M, McConnell S. Land-based exercise for osteoarthritis of the knee: a metaanalysis of randomized controlled trials. J Rheumatol. 2009;36(6):1109-1117.

84. Strine TW, Hootman JM. US national prevalence and correlates of low back and neck pain among adults. Arthritis Care Res. 2007;57(4): 656-665.

85. Vincent HK, Seay AN, Montero C, Conrad BP, Hurley RW, Vincent KR. Functional pain severity and mobility in overweight older men and women with chronic low-back pain - part I. Am J Phys Med Rehabil. 2013;92(5):430-438.

86. Vincent HK, George SZ, Seay AN, Vincent KR, Hurley RW. Resistance exercise, disability, and pain catastrophizing in obese adults with back pain. Med Sci Sports Exerc. 2014;46(9):1693-1701.

87. Vincent HK, Vincent KR, Seay AN, Conrad BP, Hurley RW, George SZ. Back strength predicts walking improvement in obese, older adults with chronic low back pain. PM R. 2014;6(5):418-426.

88. Miltner O, Wirtz DC, Siebert CH. Strengthening lumbar extensors therapy of chronic back pain - an overview and meta-analysis. Z Orthop Ihre Grenzgeb. 2001;139(4):287-293.

89. Brosseau L, Wells GA, Tugwell P, et al. Ottawa panel evidence-based clinical practice guidelines for the management of osteoarthritis in adults who are obese or overweight. Phys Ther. 2011;91(6): 843-861.

90. Brosseau L, Wells GA, Kenny GP, et al. The implementation of a community-based aerobic walking program for mild to moderate knee osteoarthritis: a knowledge translation randomized controlled trial: part II: clinical outcomes. BMC Public Health. 2012;12:1073.

91. Foroughi N, Smith RM, Lange AK, Singh MAF, Vanwanseele B. Progressive resistance training and dynamic alignment in osteoarthritis: a single-blind randomised controlled trial. Clin Biomech (Bristol Avon). 2011;26(1):71-77.

92. McKnight PE, Kasle S, Going S, et al. A comparison of strength training, self-management, and the combination for early osteoarthritis of the knee. Arthritis Care Res. 2010;62(1):45-53.

93. Lim B-W, Hinman RS, Wrigley TV, Sharma L, Bennell KL. Does knee malalignment mediate the effects of quadriceps strengthening on knee adduction moment, pain, and function in medial knee osteoarthritis? A randomized controlled trial. Arthritis Rheum. 2008;59(7):943-951.

94. Lim J-Y, Tchai E, Jang S-N. Effectiveness of aquatic exercise for obese patients with knee osteoarthritis: a randomized controlled trial. PMR. 2010;2(8):723-731.

95. Jenkinson CM, Doherty M, Avery AJ, et al. Effects of dietary intervention and quadriceps strengthening exercises on pain and function in overweight people with knee pain: randomised controlled trial. BMJ. 2009;339:b3170.

96. Messier SP, Mihalko SL, Legault C, et al. Effects of intensive diet and exercise on knee joint loads, inflammation, and clinical outcomes among overweight and obese adults with knee osteoarthritis: the idea randomized clinical trial. JAMA. 2013;310(12):1263-1273.

97. Oyeyemi AL. Body mass index, pain and function in individuals with knee osteoarthritis. Niger Med J. 2013;54(4):230-235.

98. Messier SP, Loeser RF, Miller GD, et al. Exercise and dietary weight loss in overweight and obese older adults with knee osteoarthritis: the Arthritis, Diet, and Activity Promotion Trial. Arthritis Rheum. 2004;50(5):1501-1510.

99. Campos RM, de Mello MT, Tock L, et al. Aerobic plus resistance training improves bone metabolism and inflammation in adolescents who are obese. J Strength Cond Res. 2014;28(3):758-766. 
100. Nimmo MA, Leggate M, Viana JL, King JA. The effect of physical activity on mediators of inflammation. Diabetes Obes Metab. 2013;15(s3):51-60.

101. Annesi JJ, Whitaker AC. Weight loss and psychologic gain in obese women - participants in a supported exercise intervention. Perm J. 2008;12(3):36-45.

102. Donnelly JE, Blair SN, Jakicic JM, Manore MM, Rankin JW, Smith BK. Appropriate physical activity intervention strategies for weight loss and prevention of weight regain for adults. Med Sci Sports Exerc. 2009;41(2):459-471.

103. Seagle HM, Strain GW, Makris A, Reeves RS, American Dietetic Association. Position of the American Dietetic Association: weight management. J Am Diet Assoc. 2009;109(2):330-346.

104. Rao G, Burke LE, Spring BJ, et al. New and emerging weight management strategies for busy ambulatory settings a scientific statement from the American Heart Association endorsed by the society of behavioral medicine. Circulation. 2011;124(10):1182-1203.
105. Sola K, Brekke N, Brekke M. An activity-based intervention for obese and physically inactive children organized in primary care: feasibility and impact on fitness and BMI. Scand J Prim Health Care. 2010;28(4): 199-204.

106. Khoja SS, Susko AM, Josbeno DA, Piva SR, Fitzgerald GK. Comparing physical activity programs for managing osteoarthritis in overweight or obese patients. J Comp Eff Res. 2014;3(3):283-299.

107. Haight DJ, Lerner ZF, Board WJ, Browning RC. A comparison of slow, uphill and fast, level walking on lower extremity biomechanics and tibiofemoral joint loading in obese and nonobese adults. J Orthop Res. 2014;32(2):324-330.

108. Miller GD, Nicklas BJ, Davis C, Loeser RF, Lenchik L, Messier SP. Intensive weight loss program improves physical function in older obese adults with knee osteoarthritis. Obesity. 2006;14(7):1219-1230.

109. Vincent HK, Vincent KR. Considerations for initiating and progressing running programs in obese individuals. PM R. 2013;5(6):513-519.
Journal of Pain Research

\section{Publish your work in this journal}

The Journal of Pain Research is an international, peer-reviewed, open access, online journal that welcomes laboratory and clinical findings in the fields of pain research and the prevention and management of pain. Original research, reviews, symposium reports, hypothesis formation and commentaries are all considered for publication.

\section{Dovepress}

The manuscript management system is completely online and includes a very quick and fair peer-review system, which is all easy to use. Visit http://www.dovepress.com/testimonials.php to read real quotes from published authors. 